\title{
Academic discourse socialisation challenges and coping strategies of international graduate students entering English-medium universities
}

Article

Accepted Version

Creative Commons: Attribution-Noncommercial-No Derivative Works 4.0

Wette, R. and Furneaux, C. (2018) Academic discourse socialisation challenges and coping strategies of international graduate students entering English-medium universities. System, 78. pp. 186-200. ISSN 0346-251X doi: https://doi.org/10.1016/j.system.2018.09.001 Available at https://centaur.reading.ac.uk/80144/

It is advisable to refer to the publisher's version if you intend to cite from the work. See Guidance on citing.

To link to this article DOI: http://dx.doi.org/10.1016/j.system.2018.09.001

Publisher: Elsevier

All outputs in CentAUR are protected by Intellectual Property Rights law, including copyright law. Copyright and IPR is retained by the creators or other copyright holders. Terms and conditions for use of this material are defined in the End User Agreement. 


\section{CentAUR}

Central Archive at the University of Reading

Reading's research outputs online 


\title{
Academic discourse socialisation challenges and coping strategies of international graduate students entering English-medium universities
}

\begin{abstract}
The internationalisation of higher education and current dominance of academic English has led to a significant growth in the number of international students studying in English medium universities. The University of Reading in the United Kingdom and the University of Auckland in New Zealand are two such universities, and they provide the settings for this study. While research to date has given us insights into the psychological and socio-cultural challenges faced by these students, their academic discourse socialisation difficulties have attracted less research attention. Drawing on data from narrative frames and interviews, this study explored aspects of the academic discourse socialisation of 31 incoming international graduate students from 20 countries. We found many commonalities in students' reports of their previous experience and the difficulties they were facing, including their unfamiliarity with aspects of source-based, critical, and writer-responsible writing, and self-perceived inadequacies regarding their knowledge of discipline-specific academic vocabulary, metadiscourse strategies, and the ability to compose concise, coherent texts. However, students also reported developing independent learning strategies and identifying useful sources of advice and support. Participants' reflections revealed a self-critical appreciation of and sense of responsibility for overcoming their difficulties, and a determination to achieve success in their studies.
\end{abstract}

\section{INTRODUCTION}

One consequence of the internationalisation of higher education and dominance of English as an academic lingua franca has been the significant growth in the number of international ${ }^{1}$ students who travel to English medium universities for graduate study (Fenton-Smith \& Humphreys, 2017). Two universities that host such students and provide the settings for the study are the University of Reading (UoR), where $37 \%$ of all graduate students are international students, and the University of Auckland (UoA), where 26\% are international students ${ }^{2}$. Institutions with significant numbers of international students need to have a good understanding of the challenges they are likely to face and the coping strategies they prefer so 
that they can best provide academic literacy and social support services to attract and support this important sector of the student population. International graduate students not only contribute revenue and develop understanding of intercultural communication and diversity in the host community, but may also have specialised skill sets of benefit the host country if they decide to seek employment there after graduation (Andrade, 2006). Previous research into the difficulties of international graduate students has provided insights into the psychological and socio-cultural challenges they face; however, their linguistic and academic discourse socialisation difficulties with regard to written academic literacies, and the coping strategies they develop, have attracted less attention. This is therefore the focus of our study.

\section{REVIEW OF THE LITERATURE}

Scholarly literature has contributed many insights about challenges facing international graduate students that are psychological and sociocultural in origin, and has also explored some of the academic literacy difficulties they face.

\subsection{Psychological, socio-cultural and academic discourse socialisation challenges}

Although all students face challenges in mental, emotional and social aspects of the transition to graduate study, when this shift involves a new language and culture the likelihood of difficulties increases. A common finding from research on this topic (e.g. Guilfoyle, 2006; Sato \& Hodge, 2009; Ward, Bochner \& Furnham, 2001; Zhou \& Todman, 2009) is that acculturative stress is greatest immediately after arrival, and is influenced by personal factors such as proficiency in English, preparedness, coping resources, and contextual factors including the cultural distance between home and host countries, amount of contact with the host community, and availability of social and academic support. With regard to the adjustments that international graduate students need to make, researchers in the social sciences have long been convinced of the influence of prior knowledge on future learning 
(Ausubel, 1968), particularly with regard to adult learners (Knowles, Holton \& Swanson, 1998). Two studies (Holmes, 2004; Wu \& Hammond, 2011) that investigated the experiences of East Asian students entering English-medium universities reported that they attributed their difficulties in no small part to the fact that instruction in their home countries had focused on sentence-level grammar, vocabulary and translation. Other studies (e.g. Chapdelaine \& Alexitch, 2004; Yeh \& Inose, 2003; Ward et al, 2001; Zhou \& Todman, 2009) have confirmed that a good knowledge of academic English on entry is a reliable predictor of academic success, a connection that has been endorsed by both scholars (Cooley \& Lewkowicz, 1997; Hyland, 2013), lecturers (Fenton-Smith \& Humphreys, 2017; Huang, 2010), and graduate students (e.g. Huang, 2010; Nam \& Beckett, 2011).

Academic discourse has been defined as "a complex representation of knowledge and language and identity" (Duff, 2010, p.175), and academic discourse socialisation as the processes by which novices gain full membership of their disciplinary communities (Duff, 2010). The most influential view of the socialisation process is an apprenticeship or "legitimate peripheral participation" (Lave \& Wenger, 1991) model in which novices learn primarily through explicit teaching, guidance, and feedback from experts to familiarise them with accepted linguistic and genre conventions and metadiscourse strategies, and by participating in a community of practice (Belcher, 1994). More recently, an alternative view has been proposed that defines academic socialisation as a complex, interactive process involving potentially problematic negotiations between novices, full community members, and peers from the home and host communities (Duff, 2010; Morita, 2004) and the networks of practice (Zappa-Hollman \& Duff, 2015) or social relationships that students are able to develop. Competence in academic discourse is both essential and challenging for all graduate students (e.g. Cheng, Myles, \& Curtis, 2004; Huang, 2010, Morita, 2004; Nam \& Beckett, 2011; Yeh \& Inose, 2003), who need to become familiar with disciplinary norms for variety of academic genres ranging from 
summaries and syntheses through essays to theses, grant applications and journal articles. The occluded practices and power dynamics often associated with disciplinary text production add to their difficulties (Curry, 2016).

Studies of academic discourse socialisation processes have found that, with regard to written literacies, international students can experience difficulties in planning, organising, revising and editing texts (Cooley \& Lewkowicz, 1997; Fenton-Smith \& Humphreys, 2017; Huang, 2010); in the use of discipline-appropriate metadiscourse strategies to convey stance (Hyland, 2004); and in developing authoritative authorial identities in English (Hirvela \& Belcher, 2001; Morita, 2004). With the "rehabilitation" of contrastive rhetoric (Connor, Nagelhout \& Rozycki, 2008), the contributing role of prior knowledge as negative transfer from the discourse norms of the L1 is now also acknowledged; for example, the shift from reader-responsible to writerresponsible writing (Hinds, 1987; Leki, 1991).

\subsection{Coping strategies and sources of support}

Studies that include descriptions of successful graduate students' strategies for managing the challenges of adjusting to the new academic discourse and disciplinary culture (e.g. Furneaux, 2018; Belcher 1994; Brown \& Holloway, 2008; Guilfoyle, 2006; Kuwhara, 2008; Nam \& Beckett, 2011; Okuda \& Anderson, 2018; Sato \& Hodge, 2009; Seloni, 2012; Wu \& Hammond, 2011) have revealed that students are aware of and actively engage with the challenges they face, and that they report using self-directed learning strategies such as seeking out useful practice opportunities, attending writing centre consultations, study groups and workshops, and establishing helpful, open relationships with supervisors, tutors and peers. In a study of the use of support resources by five Korean graduate students (Nam \& Beckett, 2011), they described using intertextual strategies such as writing in the L1 and translating into the 
L2, paraphrasing from sources, mining texts for useful vocabulary, compiling lists of useful lexical bundles, and using proficient texts as models.

Academic discourse socialisation into an Anglo-western university environment inevitably involves changes in aspects of students' identities, and the consensus among researchers (e.g. Brown \& Holloway, 2008; Chang \& Kanno, 2010; Kuwhara, 2008; Ward et al, 2001; Zhou \& Todman, 2009) is that stress diminishes after the first year, and that not every student experiences it to the same degree. For example, a graduate student in one study commented that by "view[ing] my professors and advanced doctoral students as mentors rather than competitors [and] by framing my early graduate school interactions as an apprenticeship relationship, I was able to maintain a healthy sense of my own identity and learn from experiences that I'd otherwise find disheartening" (Kuwhara, 2008, p.195). Evidence of a strong sense of self-efficacy was also found in a study of four mature doctoral students (Chang \& Kanno, 2010), who reported that they "viewed themselves as no less legitimate, albeit relatively new members in the English-speaking academic community, [and] as competent and legitimate members of the academic communities despite the extra linguistic and cultural barriers they encountered" (p. 689).

\subsection{The current study}

While research to date has contributed much to our understanding of the psychological, sociocultural and academic discourse socialisation challenges that students experience and the coping strategies they develop, most studies have focused on the experiences of students from East Asia, and have collected survey data from large groups (Cheng et al, 2004; Yeh \& Inose, 2003; Zhou \& Todman, 2009) or from smaller (fewer than 12) numbers of participants using interviews (e.g. Brown \& Holloway, 2008; Chang \& Kanno, 2010; Guilfoyle, 2006; Holmes, 2004; Morita, 2004; Wu \& Hammond, 2011). We found only four studies in our survey of the 
literature (Brown \& Holloway, 2008; Cheng et al, 2004; Guilfoyle, 2006; Yeh \& Inose, 2003) that included participants from a range of nationalities, and no studies that used narrative frames to elicit university students' views. In addition, although previous studies have reported on academic literacy issues as part of investigations into psychological, sociocultural and academic challenges, including the demands of participating in oral discourse (Seloni, 2012), as Okuda and Anderson (2018) point out, relatively little research (studies by Nam \& Beckett, 2011, and Séror, 2011 are noteworthy exceptions) has specifically investigated the challenges of academic socialisation to written discourse at graduate level, including the roles of various socialisation agents.

To contribute to knowledge in this area, we therefore devised a study that would elicit the views of a substantial number of graduate students from a broad a range of language backgrounds from our universities, and that would gather information about issues that we, and the research literature, identified as important and interesting. The study aimed to explore these topics: the relationship between academic writing priorities in the students' home and the host communities, the relationship between writers and sources as well as writers and readers, evaluative writing, the value of feedback, and useful sources of support. For each of these subjects, we sought answers to research questions related to what incoming graduate students need to know, how their learning progresses, and how it can best be supported. The research questions guiding the study were:

1. What knowledge and experience do current international graduate students bring with them to study in an English medium university?

2. What academic discourse socialisation challenges do they encounter?

3. What coping strategies do they draw on and develop?

4. What sources of advice and support do they find helpful? 


\section{METHODOLOGY}

This exploratory study collected data from narrative frames and semi-structured interviews.

The researchers were the authors of this article, and reported on students at their universities. Each of us has more than twenty years' experience working with international students as EAP academic writing module convenors, teachers, and supervisors of graduate students.

\subsection{Participants \& context}

The study took place at two universities in the United Kingdom and New Zealand. Participants were recruited through academic literacy courses and support programmes. As can be seen from Table 1, they came from a range of countries. Nearly two-thirds of the sample group were studying for Masters qualifications, and reported that they were required to produce academic essays and dissertations, while the others were doctoral research students. Most (25) of the group of 31 were studying in the social sciences (TESOL, applied linguistics, or education), three were from the biological sciences, and three were studying in the hard sciences.

\section{Table 1}

\subsection{Instruments and data collection}

Narrative frames (NF) were introduced as a research instrument some ten years ago (Barkhuizen \& Wette, 2008). They provide a template of connected gapped sentences for participants to complete with as much information as they wish to provide (the frames template used for this project can be viewed in Appendix A). The advantages of NF are that, although themes are nominated by the researcher, the amount and type of information are controlled by the participant, which may be less intimidating for novices since they allow time for reflection and also scaffold the reflective writing that L2 learners can find difficult. The resulting data are meaningful and able to be compared across participants, facilitating analysis. Possible disadvantages of NF for research purposes are that the choice of frames strongly influences the themes about which information is elicited, frames can be misinterpreted unless carefully 
composed and, as with interviews, information from participants will vary if they are unwilling or unable to disclose. There is also the risk that their stories can become "depersonalised" in the analysis phase (Pavlenko, 2007). For these reasons, scholars (e.g. Barkhuizen, 2014) usually advise using NFs in combination with other data sources such as interviews.

For our study, NF were emailed as Word documents to volunteer participants. They were invited to email us if any frames were unclear, and were given several weeks to complete the task of completing seven frames to produce a paragraph on each of these topics:
A. About me and my past
B. Prior knowledge and getting used to a new academic community
C. Writing using sources and developing my identity as an author
D. Managing information and interacting with the reader
E. Writing in a questioning, evaluative way
F. Learning from written feedback
G. Sources of guidance and support

The purpose of the semi-structured interviews that followed submission of the frames was to clarify and further explore NF reflections (see Appendix B). Interviews lasted 50-80 minutes; they were audio-taped and fully transcribed.

\subsection{Data analysis}

Each researcher followed the same data analysis procedures:

1. To facilitate key word searches, we copied the $31 \mathrm{NF}$ responses to each of the frame starters into Word documents for each sub-theme (e.g. A1 x 31, A2 x $31 \ldots)$.

2. We read the responses to each frame starter and "bolded" the main points to form a list for initial coding (Miles, Huberman \& Saldaña, 2014). From this list, we summarised 
common themes within each 31-response set, and organised the information (noting the number of participants who expressed each view) into theme-based tables (Tables 2-7).

3. We coded interview content into categories in the same way as the NF data, with each interview statement assigned to a particular frame and theme e.g. A1, A2.

4. We formatted Tables 2-7 to report on main themes in participants' responses to each frame starter and interview question. Those themes mentioned by fewer than four participants were omitted from the tables. Any new information noted in participants' interview statements and not captured in Step 2 (above) was added to the totals.

Each researcher independently coded the NF and interview statements of participants at her home university. Intra-rater reliability was achieved when we went back to the raw data several weeks after the initial coding and recoded any errors we identified. We then checked each other's coding, and since the structure of the frames separates statements by theme, agreement was strong (more than 90\%). Any small errors due to inconsistent or unclear coding were resolved through email discussion. Triangulation of the data was achieved by comparing interview and NF responses, and this helped to sort out occasional ambiguities.

\section{RESULTS}

This section presents findings in answer to the research questions we posed about the prior knowledge, main challenges, learning needs, and coping strategies of international graduate students. Direct quotations have been included to the fullest extent to allow for direct representation of students' voices. Summaries of comments from NF and interviews (with frequency counts in brackets) are presented in Tables 2-6.

\subsection{Prior knowledge and experience}


Table 2 describes students' previous knowledge and experience through comparisons between study at home and host institutions. As can be seen from the table, there was general consensus about differences in the types of written work assigned and the standard of work expected from undergraduates at home, and what was required of them as graduate students.

\section{Table 2}

Irrespective of their country of origin, almost all students reported having received very little in the way of explicit instruction in academic writing (either process- or genre-based), and that any tuition they had received focused on sentence and paragraph structure. They reported studying in large classes and being assessed through examinations and assignments for which they received grades or marks but little feedback. In contrast, in their current studies they were pleased to find detailed and "crystal-clear" (S30, Sudan) marking criteria, and that grades were awarded from assignment work rather than exams. Some students expressed surprise at the standard of work required and the disappointing grades they had initially received, which one described as "a bit of a reality check" (S21, Kuwait).

Students were aware of the need to become familiar with "specific conventions in writing each section of an essay" (S1, China) in a style of writing that was, they believed, more formal, and less personal than in their home countries, as well as unfamiliar in that clear, concise sentences and explicit signposting of text organisation were required. Students from China (S5), Egypt (S4) and Indonesia (S10) and Japan (S27) all reported noticing differences between the requirement for a direct style and "front-loading" of key information to develop an argument, and the less direct approach that was conventional in their home countries. One (S27) commented that "when I write English essays we tend to get straight to the point. In Japanese essays I think this might be too forceful. I go back and forth, get around the gist, and finally arrive at the point". Students from Mexico (S2), Hungary (S3) and Brazil (S8) reported another difference; namely, that their usual practice of writing long sentences with multiple items of 
information connected by commas was not acceptable. The requirements to show originality and to convey an authoritative authorial identity were noted as positive differences: "Here you can express your ideas, as long as you have support, and the teacher's opinion does not have such an influence" (S17, Cambodia); academic writing "is not about giving credit to other people, but improving yourself with your own ideas and ability" (S23, Vietnam).

\subsection{Authorial identity and writing using sources}

Students also commented on their efforts to establish an appropriate stance on source text information. Table 3 shows that most of the group had had relatively little experience of the kind of source-based writing that was required in their graduate studies, and were unused to relying on paraphrase and summary citations ("In Brazil we did a lot of big quotes, as a way of acknowledging the style of the person who first thought of the idea", S8), or to following strict rules about the amount of copied material permissible and the obligation to acknowledge all references within the text as well as in an end-of-text list. Although lacking in confidence about their current abilities, students understood how to go about developing their abilities and establishing an authorial identity. One commented on its particular importance in the initial and final sections of a text: "in the introduction you must show your interest in the topic, how you will add value, and state your agenda... in the conclusion I have more confidence to add my voice and be critical" (S28, Jordan).

\section{Table 3}

Students conceded the challenges of establishing an authoritative (but modest) identity in accordance with Anglo-western norms. One reported that in her home country "you write to present material and give evidence - it has nothing to do with you as a writer, [so] the first thing for me to learn was to have an academic voice and to project that in my writing" (S4, Egypt), and another that "it's not about taking on a new identity...but realising that I have or need to express any identity when I write something academic" (S23, Vietnam). 
Although students' narratives described their gradually developing understandings in how to use source texts in support of their own arguments, review current knowledge, and draw on metadiscourse strategies to manage information, at the same time they described the challenges of selecting sources, accurately synthesising and integrating citations from multiple sources, and conveying a stance in support of their own arguments. Awareness of current limitations in their disciplinary knowledge exacerbated this lack of confidence. Sample comments included that "the biggest difficulty is engaging in academic conversations [is that] there are a lot of implicit rules I don't understand well" (S7, Brazil); "I often tend to agree with the authors of the articles I read and I am still not confident" (S16, China); and "it's hard for me to use 'I' and self-mention because it feels not safe, and I need to be as safe as possible" (S4, Egypt). Students described employing a range of independent learning strategies that included intensive and extensive reading, analysis of expert texts as models or textual mentors, practising writing and note-taking, attending academic literacy courses, and taking up offers of feedback from teachers or peers.

\subsection{Writer-reader relationships}

The obligation for academic writers to consider the needs of their readers was an unfamiliar consideration for most students, who typically described the conventional style of writing in their home countries as formal, impersonal, elaborate, indirect, and oriented to a knowledgeable reader. One student reported that "in Brazil I had the idea that to write well I have to write complicated things, to write difficult words to show I have a broad understanding of the different words that I use because I have studied enough. The reader has to work hard" (S8). Similar practices were noted in Mexico, where scholars "will use sophisticated language so you really need to belong to the group to understand fully. They take it for granted that whoever is going to read the work will know what they are writing about" (S13).

\section{Table 4}


Interview and narrative frame comments summarised in Table 4 show that most students were aware of the need to provide the reader with coherent, well-organised, and generally readable texts that included headings and sub-headings, metadiscourse, summaries, introductory sentences, and conventional genre organisation patterns in order to connect with readers. They were aware of the need to manage the flow of information in such a way that the reader will not only find the text comprehensible, but be able to engage with their argument: the need "to persuade my readers to do something in my writing, not just leave them to decide by themselves" (S19, Kazakhstan). Another commented that a text should not be "purely receptive - it should invite discussion; you're presenting it as if it's an academic conversation, so you have to give the reader a chance to argue back" (S21, Kuwait). One student commented on differences between reader- and writer-responsible approaches by noting that "when I write Japanese essays I intentionally try to be ambiguous - it's expected, but when I write English academic essays I have to hold readers' hands throughout" (S27).

Students were not altogether confident about their abilities in this area. Several admitted that they had not developed an awareness of readers' needs, and that when they wrote they considered "just my own ideas" (S9, China) or "just the marking criteria" (S24, Vietnam). Others appeared uncertain about how to go about interacting with the reader, and acknowledged difficulties in trying to do this "while following the flow of my own ideas - I have to go back and edit that in later" (S18, Kazakhstan). Some resistance to this strategy was evident in students" comments that "interacting with the reader can be overdone" (S21, Kuwait), and that the writer "can't focus exclusively on the reader" (S29, Pakistan). There was, however, general consensus across the group that analysis of proficient or exemplary models as textual mentors, and feedback on practice drafts and instructional tasks from a peer or teacher, were valued sources of assistance for developing their abilities. 


\subsection{Critical and evaluative writing}

Table 5 summarises students' reflections on evaluative writing. Although for many students this was their first experience of writing critically, they were aware of its importance ("writing is critical thinking" (S5, China), and of the fact that disciplinary knowledge was an important requirement. One student reported that 'I'm taking a new course called 'Creativity in Teaching' which very new for me, and to critique is challenging" (S9, China). Another (S11, Bangladesh) summarised this in a comment that "If you have good English and a lot of knowledge, then you would have higher probability to think critically and to raise questions".

\section{Table 5}

Some of the group commented on the benefits of mastering this skill. One reported that being critical "allows for more creative thoughts and balancing different views"” (S17, Cambodia), while another noted that it can facilitate identification of research gaps in order "to create new knowledge" (S7, Brazil), as well as allowing writers to show their understanding of a text, a topic, or of research in their field. One student commented that "it shows that you are not only reading, but thinking about the topic" (S25, Brazil). Several acknowledged the need for student writers to add their own point of view and to "weigh" that viewpoint (S29, Pakistan). One stated a belief that "writing is a social process in which text, reader and writer are engaged and interact" (S2, Spain). With regard to the content of their evaluations, this included underlying theories, and the methodologies or findings of previous studies in relation to their disciplinary area. A quarter of the group reported evaluating the relevance of information or of a claim made in their own writing to see "how far the findings could be generalised, is the information reliable or valid, and what does the recent research say about this topic" (S31, Turkey).

The challenges of writing critically included, for half the group, being able "to maintain a critical attitude towards someone's writing who holds a higher degree, high academic reputations, and has more experience than me" (S3, Hungary). Others reported struggling to 
evaluate in academic language, with one commenting on the challenges of "avoiding vagueness or knowing when hedging is necessary" (S31, Turkey). Strategies for overcoming these difficulties echoed those expressed in Section 4.3 above with regard to writer-reader relationships. The importance of relevant reading and knowledge was noted here by over half the group, including the need "to read good examples of assignments" (S26, Greece). Some commented on the need for "learning by doing" (S28, Jordan), and the need for on-going feedback was noted: "so I can keep growing as a writer" (S2, Spain).

\subsection{Learning from feedback}

Students' previous experience of feedback on writing was that, if any, it had been almost exclusively focused on language accuracy issues. Feedback in their current studies was more varied, and included not only language but also a focus on content and on new topics such as on writing style, coherence, and "setting appropriate boundaries between my writing and source text"' (S12, Egypt). It also recognised "aspects of what my work has achieved and what it has not" (S23, Vietnam). Reflecting on the role of feedback in learning, students noted that it gave them a "clear identification of what should be done better" (S8, Brazil) and opportunities to "become aware of my typical mistakes" (S26, Japan). The feed-forward role of feedback was mentioned by a substantial number of students, with one commenting that "this feedback is very useful for the further assignments because although the content is different, the [writing] skill that is required is the same" (S19, Kazakhstan). However, a few students had reservations: "feedback can be incorporated into practice only if there are subsequent assignments of a similar type" (S16, China).

\section{Table 6}

As Table 6 shows, over half of the participants reported finding feedback on both content and language helpful, particularly if it was also "prompt, precise, and criterion-based" (S16,

China). A number of others expressed similar appreciation of detailed, personalised feedback: 
"I need examples from my own text" (S25, Brazil). Students valued guidance on text organisation, especially for genres such as research reports that were less familiar. On the other hand, they were critical of feedback that was too vague or general, such as "improve critical evaluation" (S25, Brazil). Feedback that did not identify specific examples in their texts or give guidance on how the text could be improved was seen as unhelpful, especially if the student was unfamiliar with what was expected, as exemplified in the comment that "the lecturer wanted me to relate my practice/experience more to the theories without giving some guidance how to do it" (S23, Vietnam).

Students commented favourably on new ways of working such as peer feedback: "If I could have another peer review it would be fantastic" (S16, China). Others had been encouraged to submit outlines of assignments for formative feedback, and most found this beneficial: "I got really good feedback...about structure...if I don't have clear organisation, clear structure then I cannot write them (the content) in an organised way" (S27, Japan). Several requested oral as well as written feedback from the teacher on the grounds that "feedback is more useful when it is constructed by interaction between teacher and student, whereas a written paper may be disregarded or misinterpreted" (S5, Brazil). They also wanted the possibility of face-to-face discussion after receiving written feedback: "I asked personally about the way to improve, and there were some recommendations which were not in their feedback form" (S19, Kazakhstan).

\subsection{Benefiting from available guidance and support}

As Table 7 shows, students drew on a wide range of human, paper and online resources to assist with their studies. The most commonly mentioned human resource was the dissertation or thesis supervisor, with some doctoral supervisors feeling the need to go beyond the remit of an academic advisor to "help[ed] me by correcting all the grammatical errors, indicating inappropriate language use and giving suggestions on text structure and content" (S16, China). 
Content lecturers were identified as helpful in giving feedback on writing, as were classmates and friends for advice on language and the general comprehensibility of texts. Professional proof-readers were also mentioned, and over a quarter of participants reported finding their services useful: "a proof reader is helpful...on grammar mistakes and some minor like article and a bit on coherence" (S17, Cambodia). These five groups of people gave advice on language and content, and were reported as sources of guidance that students would seek out for their future written work.

\section{Table 7}

With regard to non-human resources, half the group reflected that they used articles and books in their field of study as language and style guides as well as content resources for their own writing. One noted that "from the readings I am always putting the new words into my vocabulary bank" (S16, China), and another that "sometimes I'd circle pieces or paragraphs in articles that... are written in such a great style that if ever I'm suffering from writer's block or stuck...I glance over" (S21, Kuwait). Exemplars of students' writing in the form of completed assignments and dissertations were seen as useful by a number of students who had experienced their use in content classes: "I wouldn't get a distinction in the second language acquisition course without the help of previous people's work, because I didn't know the system. It's like an authentic example... it showed me the way" (S30, Sudan)

Half of the group reported using online sources of guidance for language (e.g. the Manchester Phrase Bank, or the Purdue Online Writing Lab), or for citation practices (e.g. APA website). In an interesting sign of the times, two reported having enrolled on academic writing MOOCs (one pre-study) to develop their skills. On-campus English for academic (EAP) purposes writing instruction was considered important by almost half of the group. While some noted a preference for the authenticity of module-specific guidance, others also expressed gratitude for 
the help of study advisors and librarians with more general writing difficulties. A third reported regular use of course guides and published textbooks on academic writing.

\subsection{Nationality groups}

We also examined statements by students from the same geographic and/or linguistic background.

\section{Middle East}

Six students came from Middle-Eastern backgrounds: two from Egypt and Kuwait, and one each from Saudi Arabia and Jordan. They all noted the need to shift to writer-responsible writing, with one commenting that in Arabic, "if you don't understand it, it's your fault; it's never the fault of the writer" (S4, Egypt). This group reported that having access to academic staff as guides, writing long texts, writing critically, and writing using sources were all new for them. The main challenges they identified were organising ideas, developing arguments, identifying key sources, critiquing texts, and using an appropriate academic style (especially vocabulary), as well as being able to "add my voice" (S12, Egypt), and fully understanding how this "allows for my writing to become part of an academic conversation" (S21, Kuwait). This student went on to describe metaphorically the importance of criticality: "Once I feel that I have shown the reader what the 'old house' looks like, the implications of its presence and its flaws, I begin to show the reader where and why and how I would like to build upon it. Finally, I express what I feel the shortcomings of what I built are in order to allow for both the reader and I to begin to think where the next improvement can be made" (S21, Kuwait).

\section{China}

The six participants from China noted key differences between current and previous academic requirements. Firstly, they reported that both the quality and quantity of reading and writing they were required to produce were significantly greater, and that the focus had shifted from 
accurate use of English in relatively short (fewer than 1000 words) "personal expression" type essays to source-based writing according to disciplinary norms. Two students also commented on the greater value placed on a direct, concise approach in their graduate studies, with one noting that in China "you must write several paragraphs of introduction before you can propose your idea, otherwise it is impolite. We take the circular approach because we want to establish a harmony with others. You describe the big context and then slowly introduce other points" (S5). Another drew attention to the fact that in their studies in China, word limits were not as restrictive, sentences and paragraphs could be longer, and the view of concise 150-word paragraphs was that they "make your writing seem too disorganised" (S6). Like students from other nationality groups, they struggled with the need to assert a convincing identity into texts when they actually "[did] not yet feel confident and authoritative" (S16).

\section{Brazil, Mexico and Spain}

Reports from the three participants from Brazil and one each from Spain and Mexico had much in common with those of other students. They described difficulties adhering to the requirement to follow precise rules and requirements with regard to word count, sentence structure and "pre-shaped" formats such as moves and steps in a research report, as well as conventional paragraph and essay structures. They pointed out that in Spanish and Portuguese it was conventional to write long (5-6 line) sentences with multiple elements joined by commas. Although they were more accustomed to source-based writing than other groups, they found the requirement to synthesise large chunks of source texts (rather than using quotations), and to take a personal stance on the content of their texts, challenging. One student noted that "in Brazil if you put anything that is your opinion you have to be very careful in the way you write it so it sounds that it's not your opinion, that it's what everybody considers. You cannot be personal at all" (S25). Another pointed out that since writing in their home country was reader-responsible there was "no need to make it easier for the reader" (S7, Brazil). 


\section{DISCUSSION}

These findings indicate that international graduate students entering English-medium universities now are reporting the same challenges as those reported in research of 10-20 years ago, and that the stark differences between the kind of academic discourse and writing instruction that they are familiar with from undergraduate study in their home contexts, whether that be Brazil, China, or Egypt, have changed little over this period. Moreover, although students' previous experience of writing instruction in English is likely to have focused on linguistic accuracy, they are likely to report that academic English proficiency still presents challenges for them. In our opinion, one of the most interesting findings of the study was the extent of the congruence within (See Section 4.7) and across the nationality groups, and the apparent "outlier" status of increasingly powerful Anglo-western academic literacy norms (Lillis \& Curry, 2010). Most of the reported diversity was actually between individual participants, and is likely to be due to differences in their academic English proficiency and amount of experience of writing in Anglo-western academic contexts.

On the whole, participants considered that previous undergraduate writing instruction had not provided an adequate preparation for graduate study in an English-medium university, particularly with regard to academic literacy norms and the construction of core genres. They also reported that, no doubt influenced by class sizes and teacher workloads, the texts they submitted for assessment at home rarely received the kind of constructive, mediated feedback that their current advisors or teachers provided. Key challenges needing to be faced by incoming graduate students included adjusting to a writer-responsible and reader-oriented approach, and learning to write in the clear, concise, direct, non-repetitive style valued in Anglo-western contexts. As well as accurately synthesising source text content, students realised that they needed to learn how to display a stance on their sources and an authoritative, 
questioning voice in their texts. The difficulties they experienced on the way to becoming proficient in these skills were, as several reported, exacerbated by the amount of "unlearning" they were obliged to do from their home writing cultures.

Despite the advances of technology available to students (e.g. the Purdue Online Writing Lab., the Manchester Phrase Bank) and in confirmation of previous findings about the relational aspect of academic discourse socialisation (e.g. Guilfoyle, 2006; Nam \& Beckett; Sato \& Hodge, 2009), students' preferred strategies were to seek out support and practice opportunities from scheduled courses and online resources, request feedback sessions with supervisors, tutors, and peers, recognising the need to develop supportive relationships with all three groups. Like the Korean students in the study by Nam and Beckett (2011), participants described trying to develop an awareness of their own language learning needs and a repertoire of learning strategies, as well as utilising proficient but achievable models as textual mentors.

Admittedly, the vast majority of graduate students, irrespective of their language background, need to progress their abilities in academic literacies; however, students in this study were required to master - quickly and with little preparation - advanced disciplinary literacies in a second language in an Anglo-western disciplinary culture. The challenges of these socialisation processes are numerous, varied, and intensified by the fact that norms and practices are opaque and often not made explicit to students. Our findings therefore underline the relevance of Hyland's comment that "writing is a cultural resource, and different genres and rhetorical conventions operate in different settings. Simply, good writers are people who are better able to imagine how their readers will respond to their texts because they are familiar with the conventions and expectations that operate in those [particular] settings" (2003, p. 48). 
We can see a number of implications arising from the results of this study for provision of writing support within institutions and disciplines. Our findings support the conclusions of previous researchers (e.g. Allison, Cooley, Lewkowicz \& Nunan, 1998; Sato \& Hodge, 2009) about the need for consistent support across disciplines in the form of workshops and regular meetings for student cohorts, and facilitation of peer and mentor-novice support relationships. There is also a need for supervisors and teachers to have an explicit awareness of the challenges posed by home culture and mother-tongue learning history and their role in the difficulties students experience in adapting to the new academic setting and the extent to which alternative ways of structuring texts can be recognised; in other words, going beyond the "deficit" model of home culture influences. The study has provided clear evidence of the extent to which students are able to independently activate resources and strategies to progress their abilities; however, participants also acknowledged the particular value of support provided by supervisors, teachers and capable peers with knowledge of both content and language. The value of explicit generic or discipline-specific writing instruction for making implicit aspects of academic literacies transparent to newcomers also needs to be appreciated. Where generic academic writing provision is offered, it needs to focus on developing students' capabilities in areas identified by students as both important and challenging; for example, academic vocabulary, grammar and linkers; patterns of organisation in genres; summarising skills; “noticing" skills in reading; and understanding task rubrics and criteria. Duff (2010, p. 187) notes the need to "increase the metadiscursive support made available to students and instructors to enhance the quality of language and literacy socialization...and to accommodate and support newcomers" to the discourse community.

Writing support in the disciplines can use examples of the work of expert as well as accomplished student writers as textual mentors for new international graduate students. Worthwhile topics for discussion with students would include how to use reading in successful 
writing, how to use one's own experience and to develop an authorial presence, how to ensure that the needs of readers are being met, and how to benefit from feedback.

The study acknowledges a number of limitations common to small-scale, exploratory studies of this type. Firstly, the NF elicited information that varied in terms of the amount of information provided and the degree of self-awareness articulated by each participant. However, the frames constituted only the first stage of data collection, and they were very useful for providing information that could be clarified and expanded in interviews. Students' views on the process of completing the NF frequently noted that the frames had activated their thinking about certain topics, offered time to think, reflect, remember, and to give "self-feedback" (S14), and had kept them "on track" (S3) by narrowing the topics and selecting what was relevant for each theme. It therefore appears that providing an opportunity for novices to prepare for or rehearse for interview questions may be a useful strategy when interviewers are native speakers of English and academic staff members and interviewees are students who may have limited knowledge, experience, or confidence in discussing the topics of interest (Hobbs \& Kubanyiova, 2008). Other limitations are that while the study collected reflections and reported experiences, no information about students' actual level of ability was assessed through textual analysis, and no comments were elicited from tutors or supervisors. In addition, since our sample was small in comparison with the size of the international graduate student population and restricted to two English-medium universities, the claims and implications that we have drawn from it can be only suggestive.

\section{CONCLUSION}

This study has extended our understanding of the experiences of international students as they manage the demands of postgraduate writing in two Anglo-western higher education contexts. Although studying on different sides of the globe and in a variety of disciplines, these students 
appeared to share many similar experiences in both host and home countries, face similar challenges, and to be in the process of developing strategies for coping with these difficulties. We were impressed by their self-critical appreciation of and sense of responsibility for overcoming the various academic discourse socialisation challenges they faced, as was evident in this comment from one student (S25, Brazil) on the subject of writing critically: "I think I still need to work a bit more on it... and a bit more on structuring my sentences. But I think I can get there because I see how much I have changed from the beginning, so I think I can get there." Our findings have also shown what can be revealed by the powerful qualitative research tools of narrative frames and follow-up interviews. It is hoped that future researchers will use these tools to further explore the experiences of other international students undertaking studies in English-medium contexts.

\section{Note}

1. International NNSE students are non-native speakers of English and are holders of student visas that permit them to undertake tertiary study.

2. We obtained this information in July, 2018 from the Planning and Strategy Office at the University of Reading, and the International Office at the University of Auckland.

\section{References}

Allison, D., Cooley, L., Lewkowicz, J., \& Nunan, D. (1998). Dissertation writing in action: The development of a dissertation writing support program for ESL graduate research students. English for Specific Purposes, 17, 199-217.

Andrade, M.S. (2006). International students in English-speaking countries: Adjustment factors. Journal of Research in Education, 5, 131-154.

Ausubel, D.P. (1968). Educational psychology: A cognitive view. New York: Holt, Rinehart \& Winston.

Barkhuizen, G. (2014). Revisiting narrative frames: An instrument for investigating language teaching and learning. System, 47, 12-27.

Barkhuizen, G. \& Wette, R. (2008). Narrative frames for investigating the experiences of language teachers. System, 36, 372-387. 
Belcher, D. (1994). The apprenticeship approach to advanced academic literacy: Graduate students and their mentors. English for Specific Purposes, 13, 23-34.

Brown, L. \& Holloway, I. (2008). The adjustment journey of international postgraduate students at an English university. Journal of Research in International Education, 7, 232249.

Chang, Y. \& Kanno, Y. (2010). NNES doctoral students in English-speaking academe: The nexus between language and discipline. Applied Linguistics, 31, 671-692.

Chapdelaine, R.F. \& Alexitch, L.R. (2004). Social skills difficulty: Model of culture shock for international graduate students. Journal of College Student Development, 45, 167-184.

Cheng, L., Myles, J., \& Curtis, A. (2004). Targeting language support for non-native Englishspeaking graduate students at a Canadian university. TESL Canada Journal, 21, 50-71.

Connor, U., Nagelhout, E., Rozycki, W. (Eds.). (2008). Contrastive rhetoric: reaching to intercultural rhetoric. Philadelphia: Benjamins.

Cooley, L. \& Lewkowicz, J. (1997). Developing awareness of the rhetorical and linguistic conventions of writing a thesis in English: addressing the needs of EFL/ESL postgraduate students. In A. Duszak (Ed.), Culture and styles of academic discourse (pp. 113-129). New York: Mouton de Gruyter.

Curry, M.J. (2016). More than language: graduate student writing as "disciplinary becoming". In S. Simpson, N.A. Caplan, M. Cox \& T. Phillips (Eds.), Supporting graduate student writers: Research, curriculum \& program design (pp. 78 - 96). Ann Arbor: University of Michigan Press.

Duff, P. (2010). Language socialization into academic discourse communities. Annual Review of Applied Linguistics, 30, 169-192.

Fenton-Smith, B. \& Humphreys, P. (2017). Language specialists' views on the academic language and learning abilities of EAL postgraduate coursework students: towards an adjunct tutorial model. Higher Education Research \& Development, 36, 280-296.

Furneaux, C. (2018). Transitions into post-graduate study: Developing writers at a British university In K. Spelman Miller \& M. Stevenson (Eds.), Transitions in Writing (pp. 4771). Leiden, the Netherlands: Brill.

Guilfoyle, A. (2006). Understanding key dimensions of international postgraduate student transition and learning experiences. International Journal of Learning, 13, 71-78.

Hinds, J. (1987). Reader versus writer responsibility: A new typology. In U. Connor \& R. Kaplan (Eds.), Writing across languages: Analysis of L2 text (pp. 141-152). Reading, MA: Addison Wesley.

Hirvela, A. \& Belcher, D. (2001). Coming back to voice: The multiple voices and identities of mature multilingual writers. Journal of Second Language Writing, 10, 83-106.

Hobbs, V. \& Kubanyiova, M. (2008). The challenges of researching language teachers: What research manuals don't tell us. Language Teaching Research 12, 495-513.

Holmes, P. (2004). Negotiating differences in learning and intercultural communication. Business Communication Quarterly, 67, 294-307.

Huang, L. (2010). Seeing eye to eye? The academic writing needs of graduate and undergraduate students; from students' and instructors' perspectives. Language Teaching Research, 14, 517-539.

Hyland, K. (2003). Second language writing. Cambridge: Cambridge University Press 
Hyland, K. (2004). Disciplinary interactions: metadiscourse in L2 postgraduate writing. Journal of Second Language Writing, 13, 133-151.

Hyland, K. (2013). Writing in the university: Education, knowledge and reputation. Language Teaching, 46, 53-70.

Knowles, M.S., Holton, E.E., \& Swanson, R.A. (1998). The adult learner. (5 ${ }^{\text {th }}$ edn.).Houston: Gulf Publishing.

Kobayashi, M., Zappa-Hollman, S., \& Duff, P.A. (2017). Academic discourse socialisation. In P.A. Duff \& S. May (Eds.), Language Socialisation (pp. 239-254). Cham: Springer.

Kuwhara, N. (2008). It's not in the orientation manual: How a first-year doctoral student learned to survive in graduate school. In X. Li \& C. Casanave (Eds.), Learning the literacy practices of graduate school (pp. 186-200). Ann Arbor: University of Michigan Press.

Lave, J. \& Wenger, E. (1991). Situated learning: Legitimate peripheral participation. New York: Cambridge University Press.

Leki, I. (1991). Twenty-five years of contrastive rhetoric: Text analysis and writing pedagogies. TESOL Quarterly, 25, 123-143.

Lillis, T. \& Curry, M.J. (2010). Academic writing in a global context: The politics and practices of publishing in English. New York: Routledge.

Miles, M.B., Huberman, A.M., \& Saldaña, J. (2014). Qualitative data analysis: A methods sourcebook $\left(3^{\text {rd }}\right.$ ed. $)$. Thousand Oaks: Sage.

Morita, N. (2004). Negotiating participation and identity in second language academic communities. TESOL Quarterly, 38, 573-603.

Nam, M. \& Beckett, G.H. (2011). Use of resources in second language writing socialization. TESL-EJ, 15, 1-20.

Okuda, T. \& Anderson, T. (2018). Second language graduate students' experiences at the writing center: A language socialization perspective. TESOL Quarterly, 52, 391-413.

Pavlenko, A. (2007). Autobiographic narratives as data in applied linguistics. Applied Linguistics, 28(2), 163-188.

Sato, T. \& Hodge, S.R. (2009). Asian international doctoral students' experiences at two American universities: Assimilation, accommodation, and resistance. Journal of Diversity in Higher Education, 29, 136-148.

Seloni, L. (2012). Academic literacy socialization of first year doctoral students in USA: A micro-ethnographic perspective. English for Specific Purposes, 31, 47-59.

Séror, J. (2011). Alternative sources of feedback and second language writing development in university content courses. The Canadian Journal of Applied Linguistics, 14, 118-143.

Ward, C., Bochner, S., \& Furnham, A. (2001). The psychology of culture shock. $2^{\text {nd }}$ ed. Hove: Routledge.

Wu, W. \& Hammond, M. (2011). Challenges of university adjustment in the UK: A study of East Asian Master's degree students. Journal of Further and Higher Education, 35, 423438.

Yeh, C.J. \& Inose, M. (2003). International students' reported English fluency, social support satisfaction, and social connectedness as predictors of acculturative stress. Counselling Psychology Quarterly, 16, 15-28. 
Zhou, T. \& Todman, J. (2009). Patterns of adaptation of Chinese postgraduate students in the United Kingdom. Journal of Studies in International Education, 13, 467-486. 


\section{Frame \#A. About me and my past}

1. My name is .... and I come from (country)

2. I have a ...........degree in (subject) from my home country.

3. I am studying for a ............. degree in ................ at the University of UoA/UoR.

4. In general, I have found that studying at this university is different in that

5. ;however, in some ways it's similar; for example

6. The future goals that I hope success in my studies here in UoA/UoR will help me achieve are (your goals)

7. I decided to come to this university because

\section{Frame \#B. Prior knowledge and getting used to a new academic community}

1. When I was at university in my home country, for our studies we had to write

2. We learned about academic writing from and by doing

3. Since I started at UoA/UoR, I've noticed (no, some, many) differences in what is required by lecturers in written assignments; for example

4. When I was preparing an assignment(s) for my studies at UoA/UoR, the main difficulty(ies) that I experienced was/were

5. So far, the things I find most challenging about writing in my studies at UoA/UoR are

6. I think I'm making progress. The main thing I have learned so far about academic writing in my studies here in UoA/UoR is that

7. However, I want to learn more about.

\section{Frame \#C. Writing using sources and developing my identity as an author}

1. I understand that writing using sources is an essential academic writing skill because

2. For example, when I wrote a recent assignment, I tried to follow the rules about using sources by

3. My understanding of the term "authorial identity" is that I also need to.

4. When I wrote a recent assignment, I tried to establish my identity as author of the text through

5. I think I'm making progress in being able to refer to external sources and at the same time establish my own identity in my writing. However, I find some aspects of it challenging, such as

6. What would help to me develop my ability in this area is

\section{Frame \#D. Managing information and interacting with the reader}

1. I understand that the writer needs to manage the flow of information, and help readers to "navigate" their way through the text. This is really important because

2. When I wrote a recent assignment, I did these things to try to help the reader of my text: ... 
3. I think I'm making progress in being able to manage information and interact with the reader. However, I find challenging.

4. What would help to me develop my ability to manage information and interact with the reader is

\section{Frame \#E. Writing in a questioning, evaluative way}

1. I understand that academic writing requires writers to question and evaluate their reading, and their own arguments. This is really important because.

2. When I wrote a recent assignment, I questioned/ evaluated the following things:

3. I think I'm making progress in being able to write in a questioning, evaluative way.

4. However, I still find it challenging to

5. What would help to me develop my ability to question and evaluate in my writing is.

\section{Frame \#F. Learning from written feedback}

1. I understand that feedback on writing can help students learn by....

2. In my previous study, the focus of feedback was .....

3. Feedback from my lecturers here in /UoA/UoR focuses on

4. Aspects of feedback on written work that I have received here that I find helpful are......

5. ; however I don't find it helpful if/when ....

6. Things I have learned from feedback on a recent assignment are that...........

7. Feedback on assignments that would help me learn more would ....

\section{Frame \#G. Sources of guidance and support}

1. I know that there are people who can help me with my writing. They are....

2. The person who has helped me most with my writing at UoA/UoR is....

3. She/he helped me by

4. The sources of support that have helped me most with my writing at UoA/UoR are....

5. They helped me by....

6. When writing a recent assignment, I received help from

7. He/she helped me by

8. I also consulted the following resources

9. They helped me by

10. Looking ahead to my next assignment, people who could help me improve my writing are......

11. Other sources of guidance (eg books/online sources) that could help me improve my future assignments are. 


\section{Appendix B: Interview questions}

1. Can you tell me about where you come from, and how you came to New Zealand (NZ) the United Kingdom (UK) for your graduate studies?

2. Were there changes in your subject choices between your undergraduate and graduate studies?

3. What kinds of writing did you do before coming to NZ/UK?

4. What kinds of reading did you do before coming to NZ/UK?

5. What differences have you noticed in the texts you produce in NZ/UK (prompts: genre organisation, writer-responsibility, degree of formality/ impersonality)?

6. What differences have you noticed in the expectations and feedback from your lecturers in your home country and NZ/UK?

7. What are the main challenges you are currently facing in source-based writing?

8. How do you try to make the content of your writing meaningful - to you?

9. How and in what parts of the text do you try to express a clear identity?

10. Do you feel like you are taking on a new identity as an academic writer in NZ/UK?

11. What knowledge/personal resources do you draw on when you are trying to create some visibility for yourself as author/manager of the text? How do you do this?

12. Do you have a reader in mind when you are writing?

13. How do you manage the way the text is read, so the reader gets the information you want them to get and reads the text in the way you want it to be read?

14. Why is it important to manage the information you present in the text? (Can it be too controlling?)

15. How you approach the "questioning/evaluative" side of academic writing in your disciplinary area? How easy/difficult do you find this?

16. What might help you to do this better?

17. How might the texts that you read be a helpful resource for your writing?

18. Describe the most helpful type of feedback you can get on your writing...

19. What is the value of different types of assistance: subject knowledge, explicit writing instruction, peer review, self-reflection, feedback, practice...? (what you described in your frames)

20. Where do you see yourself on the trajectory of becoming an academic writer?

21. What have you learned/mastered?

22. What are your main concerns and challenges from here on?

23. Do you have any other comments about academic writing at the UoA/UoR?

24. Do you have any comments about completing the frames? 
Table 1.

Participant information $(\mathrm{n}=31)$

\section{Description Number}

Institution

University of Reading, United Kingdom 14

University of Auckland, New Zealand 17

Countries of origin

East Asia: China, Indonesia, Japan, Malaysia, Cambodia, Vietnam 12

West Asia: Bangladesh, Pakistan, Kazakhstan, Turkey 5

The Middle East: Egypt, Kuwait, Saudi Arabia, Jordan, Sudan 7

Europe: Spain, Greece, Hungary 3

Central \& South America: Mexico, Brazil 4

Graduate study

$\begin{array}{ll}\text { Masters } & 19\end{array}$

$\begin{array}{ll}\text { Doctoral } & 12\end{array}$

Disciplines

Applied Linguistics/ TESOL/Education 25

Biological Sciences 3

Engineering and Physics 3 
Table 2.

Summary of students' reflections on studying in their home and host tertiary institutions (Frames A-C)

\begin{tabular}{ll}
\hline \multicolumn{1}{c}{ Theme } & \multicolumn{1}{c}{ Summaries of main theme } \\
\hline Assessed products & Writing as an undergraduate in home tertiary institutions \\
Instruction & $\begin{array}{l}\text { Focus on sentence-level accuracy \& paragraphs (15) } \\
\text { Very little/no instruction on writing critically (14) }\end{array}$ \\
Feedback & $\begin{array}{l}\text { Typically none or very little - mark only with no explicit criteria (12); accuracy errors } \\
\text { only (5) }\end{array}$ \\
More descriptive, elaborate, spiral/oblique; more formal, less personal; long sentences \\
with many information elements (15)
\end{tabular}

*In Tables 2-7, the bracketed numbers refer to the numbers of students (from a total of 31) who made comments on this theme in their narrative frames and/or interviews. 
Table 3

Summary of students' reflections on writer-source relationships (Frame C)

\begin{tabular}{|c|c|}
\hline Theme & Details of theme \\
\hline \multirow[t]{2}{*}{$\begin{array}{l}\text { Experience from home } \\
\text { country }\end{array}$} & $\begin{array}{l}\text { Source text use much less important - main source was lecture notes or course text; in- } \\
\text { text referencing not required; smaller number of stipulated sources; patchwriting } \\
\text { acceptable; main form of assessment (open book) exams; frequent use of quotations to } \\
\text { show how the originator expressed an idea is acceptable (16) }\end{array}$ \\
\hline & Access to current or any journal articles or books difficult; poor library resources (6) \\
\hline \multirow[t]{3}{*}{$\begin{array}{l}\text { Meaning of authorial } \\
\text { identity }\end{array}$} & $\begin{array}{l}\text { Authorial identity }=\text { to express own views/perspective } \& \text { achieve visibility }(21) \text {, } \\
\text { established by connecting sources with own argument } \& \text { evaluative comments (16) and } \\
\text { through reporting verb choice \& metadiscourse strategies (6) }\end{array}$ \\
\hline & The need to integrate sources as authoritative support for own arguments (26) \\
\hline & $\begin{array}{l}\text { Establish identity in the introduction, make it evident in the literature review, and } \\
\text { strongly visible in the conclusion/Discussion (6) }\end{array}$ \\
\hline \multirow{5}{*}{$\begin{array}{l}\text { Experience in } \\
\text { Auckland/ Reading }\end{array}$} & Paraphrasing, summarising, quoting with acknowledgement (11) \\
\hline & Following formatting conventions (APA) accurately (10) \\
\hline & Citing a number of sources to support my argument (8) \\
\hline & Establishing authorial identity using metadiscourse strategies (7) \\
\hline & $\begin{array}{l}\text { Establishing authorial identity by evaluating sources and linking them to own arguments } \\
\text { (23) }\end{array}$ \\
\hline \multirow[t]{6}{*}{ Challenges } & Making own voice/stance/viewpoint clear when writing using sources (21) \\
\hline & Paraphrasing accurately \& avoiding plagiarism (8) \\
\hline & Integrating sources with own arguments (5) \\
\hline & Synthesising multiple sources into group citations (8) \\
\hline & Using self-mention and other types of metadiscourse (6) \\
\hline & Lack of knowledge to be authoritative and to evaluate the work of published experts (5) \\
\hline \multirow[t]{4}{*}{ Coping strategies } & $\begin{array}{l}\text { Becoming more knowledgeable in my research area; internalising key concepts; reading } \\
\text { thoroughly, widely and critically (16) }\end{array}$ \\
\hline & $\begin{array}{l}\text { Noting own ideas separately before and while reading (and avoiding the practice of } \\
\text { simply highlighting \& copying chunks from different sources into drafts) (7) }\end{array}$ \\
\hline & $\begin{array}{l}\text { Viewing texts as "a platform to launch own ideas" and arguments; finding "gaps" in } \\
\text { current knowledge; focus on the contribution of own study (7) }\end{array}$ \\
\hline & $\begin{array}{l}\text { Attending intensive courses, workshops and/or tutorials, attending to feedback on } \\
\text { practice texts (5); writing practice (10); using published texts as models (5) }\end{array}$ \\
\hline
\end{tabular}


Table 4

Summary of students' reflections on writer-reader relationships (Frame D)

\begin{tabular}{|c|c|}
\hline Theme & Details of theme \\
\hline $\begin{array}{l}\text { Experience from home } \\
\text { country }\end{array}$ & $\begin{array}{l}\text { A "reader responsible" culture, in contrast to a "writer responsible" culture in an Anglo- } \\
\text { western university }(25)\end{array}$ \\
\hline \multirow{3}{*}{$\begin{array}{l}\text { Importance of } \\
\text { connecting with the } \\
\text { reader }\end{array}$} & Logical organisation ensures that the readers doesn't get "lost" or confused (15) \\
\hline & Helps readers to follow the writer's argument/line of thought/stance (12) \\
\hline & Because the writer is part of a "conversation" with the reader (11) \\
\hline \multirow[t]{5}{*}{ Strategies } & Writing clearly/coherently (6) \\
\hline & $\begin{array}{l}\text { Using conventional patterns of organisation for a genre e.g. (sub)headings \& sections; } \\
\text { steps, moves (14) }\end{array}$ \\
\hline & $\begin{array}{l}\text { Using metadiscourse strategies to highlight importance and different thought } \\
\text { relationships (14) }\end{array}$ \\
\hline & Foreshadowing and summarising (6) \\
\hline & Composing in clear sentences and paragraphs with topic sentences in initial position (9) \\
\hline \multirow[t]{5}{*}{ Challenges } & Writing clear sentences and paragraphs (5) \\
\hline & Making decisions about how to organise longer texts (5) \\
\hline & Coherent development of an argument in a long text (8) \\
\hline & $\begin{array}{l}\text { Judging the appropriate relationship between writer and reader: personal \& impersonal; } \\
\text { formal \& informal elements (5) }\end{array}$ \\
\hline & Reconciling this focus with the need to convey the writer's argument/ideas (4) \\
\hline \multirow[t]{3}{*}{ Coping strategies } & Using published texts e.g. articles, chapters, theses as text mentors (14) \\
\hline & Practice and feedback (11) \\
\hline & Learning from a more expert peer or supervisor (4) \\
\hline
\end{tabular}


Table 5

Summary of students' reflections on evaluative writing (Frame E)

Theme

Experience from home country

View of critical writing

Features evaluated in writing

Challenges

Coping strategies

\section{Details of theme}

Critical writing not required (5) - descriptive writing, or focussed on linguistic accuracy (especially grammar)

Helps the writer interpret/explain his/her own arguments for the reader (11)

Critical examination of the research context and identification of a niche for future research (9)

Critical thinking (analysis and evaluation of an issue to develop an opinion or argument (6)

Need to add own perspective, and not just present other people's views (5)

Need for interaction between writer and reader (5)

Reflects the writer's understanding of a topic (4)

Underlying theory/methodology/findings of previous studies (17)

Relevance of an item of information/a claim (8)

Coherence and relevance of own claims (4)

Critical evaluation of authoritative sources (15)

Evaluating in an academic/persuasive way (7)

Critical synthesis of previous research (4)

Reading published articles (topic-related) (17)

Practice (13)

Feedback from supervisors and peers (5) 
Table 6

Summary of students' reflections on feedback sources (Frame F)

\begin{tabular}{|c|c|}
\hline Theme & Details of theme \\
\hline \multirow{3}{*}{$\begin{array}{l}\text { Experience from home } \\
\text { country }\end{array}$} & Focus on language: grammar, vocabulary, spelling (21) \\
\hline & Focus on content $(5)$ \\
\hline & No feedback, beyond a mark (5) \\
\hline \multirow{4}{*}{$\begin{array}{l}\text { How feedback can help } \\
\text { in learning }\end{array}$} & By identifying and correcting errors (linguistic, appropriacy) (9) \\
\hline & Through guidance on alternatives/improvements (9) \\
\hline & Through feedback on an outline (9) \\
\hline & By providing opportunities for students to reflect on their own errors (7) \\
\hline \multirow{5}{*}{$\begin{array}{l}\text { Experience of feedback } \\
\text { in graduate studies }\end{array}$} & On content/argument (15) \\
\hline & On inaccurate/inappropriate language (12) \\
\hline & On writing style and writing analytically (8) \\
\hline & Using feedback on one piece of work for future assessed work (8) \\
\hline & On use of sources (6) \\
\hline \multirow{4}{*}{$\begin{array}{l}\text { Feedback found to be } \\
\text { helpful }\end{array}$} & On text content (17) \\
\hline & On language: grammar, vocabulary, spelling (16) \\
\hline & Detailed/precise explanations of errors/weaknesses; how the text can be improved (11) \\
\hline & On text organisation (8) \\
\hline \multirow{2}{*}{ Unhelpful feedback } & Vague; too general (10) \\
\hline & Comments without clear evidence/examples in the text or suggested improvements (9) \\
\hline \multirow{3}{*}{$\begin{array}{l}\text { Learning from recent } \\
\text { experience of feedback }\end{array}$} & Language issues (7) \\
\hline & Paragraph-level coherence (5) \\
\hline & How to be critical (5) \\
\hline \multirow{5}{*}{$\begin{array}{l}\text { Feedback that would } \\
\text { help learning }\end{array}$} & Being able to discuss feedback with the teacher (11) \\
\hline & Suggestions for improvement (7) \\
\hline & Comments on content and language (re accuracy errors) (6) \\
\hline & Peer review (5) \\
\hline & Feedback that included examples (5) \\
\hline
\end{tabular}




\section{Table 7}

Summary of students' reflections on sources of guidance and support (Frame G)

\begin{tabular}{ll}
\hline Theme & \\
\hline $\begin{array}{l}\text { Sources of guidance } \\
\text { and support }\end{array}$ & Content lecturer/supervisors (15) \\
& Language advisors and workshops (11) \\
& Peers (9) \\
& Proofreaders (4) \\
& Academic writing teachers (4) \\
The person who has & Dissertation supervisor (12) \\
helped most & Writing teachers (9) \\
& Module tutor/content teacher (5) \\
$\begin{array}{l}\text { Type of assistance from } \\
\text { human source }\end{array}$ & Grammar and vocab (7) \\
& Appropriate content (6) \\
How to improve writing in general (5) \\
$\begin{array}{ll}\text { Other sources of } \\
\text { support }\end{array}$ & $\begin{array}{l}\text { Academic articles/books in my field of study (15) } \\
\text { Online sources/software (eg Manchester phrase bank, Purdue Online Writing Lab.) (15) }\end{array}$ \\
& Writing course instruction and assignments (13) \\
& Writing course guides and textbooks (12) \\
Wype of assistance from & Information about specific academic writing requirements (12) \\
Lother sources & Language and text structure (6) \\
Help in a recent & From peer review (10) \\
assignment & Content lecturer (5) \\
Planned support for & Peers or other friends (10) \\
next assignment & Content lecturers (8) \\
Supervisor (7) & Proofreader (6) \\
& Books about academic writing (7) \\
Online sources (6) \\
Model student writing exemplars (4) \\
Attending writing support centres (4) \\
\\
\hline
\end{tabular}

